\title{
STRUCTURE AND SPECTROSCOPY OF SELECTED LANTHANIDE COMPOUNDS WITH COORDINATION NUMBER FROM 9 TO 6
}

\author{
J. LEGENDZIEWICZ \\ Faculty of Chemistry, University of Wrocław \\ F. Joliot-Curie 14, 50-383 Wrocław, Poland
}

The lecture deals with a group of lanthanide compounds in which some structural factors infuence, in a special way, spectroscopic properties of the systems under investigation. The following systems were chosen: three with polymeric structure, two of the dimer type, one a pseudo-dimer system with coordination number (C.N.) $=7$, and an octahedral compound of $\mathrm{LnL}_{6}$ type. The crystal structures of the systems under consideration will be shown, their absorption and excitation spectra will be presented and confronted with X-ray data. Radiative and nonradiative processes will be considered and the role of cooperative interactions analyzed. Some aspects of dynamics in solids will be done, too.

PACS numbers: $61.66 . F n, 78.20 . \mathrm{Dj}, 78.20 . \mathrm{Wc}, 78.55 . \mathrm{Hx}, 78.66 .-\mathrm{w}$

\section{Introduction}

The aim of this lecture is to deal with a group of lanthanide compounds in which some structural factors influence, in a special way, the spectroscopic properties of systems under investigation. To show the effect of the creation of the polymeric chain and its spectroscopic consequences we have chosen three systems with polymeric structure: (a) single crystal of lanthanide complex with diglicine, (b) lanthanide hydroxyperchlorates, and (c) lanthanide squarates.

Complexes with iso-leucine (DL- and L-) and with aminohydroxamic acid belong to the second type of compounds and create dimers in solid state.

The next system which will be the subject of our considerations is a pseudo-dimer system, built up of lanthanide complexes of the type $\mathrm{Hg}-\mathrm{Ln}$ with coordination number (C.N.) $=7$, while the last will be an octahedral compound with C.N. $=6$.

The investigation of the structure and spectroscopic properties of lanthanide systems which create polymeric and dimeric structures are of interest for two reasons. First of all, these compounds could be used as potential up-conversion laser materials. On the other hand, the most of biologically important processes, like energy transfer and electron transfer, depend strongly on the structure of compound, 
especially on the dimensionality of systems. The results of our investigation presented here concern the second group of compounds. However, some spectroscopic results could be sufficiently interesting also for processes involved in the first type of applications.

Lanthanide ions are widely applied as metal probes in studies of biomolecular structure; thus, the studies of lanthanide ions interactions with simple peptides and aminoacids in solid state should be a valuable tool in understanding more complicated systems. Few years ago we undertook studies of X-ray and spectroscopic properties of lanthanide monocrystals with dipeptides and aminoacids, their phosphonic analogues and, more recently, with amino derivatives of hydroxamic acids. The latter compound is important in explaining the role of metal ion in the series of enzymatic processes. In [1,2] (Table 1) there are listed the lanthanide compounds whose spectroscopic properties will be here considered in relation to their structural data. It was shown that the $\operatorname{Ln}: \mathrm{A}(\mathrm{A}-$ aminoacid) ratio of a compound may influence the way of formation of polymer, and can also change the bonding mode of carboxyl group.

Besides several structural factors which were determined by X-rays, it was also stated that the coordination mode of particular aminoacid residues of peptides involved in bonding lanthanide ions is the same as in complexes with respective simple aminoacids.

\section{Polymeric and dimeric systems}

Figure 1 shows the endless chain which is formed of centrosymmetric dimeric subunits in the structure of $\mathrm{Nd}(\mathrm{Gly}-\mathrm{Gly})_{2}\left(\mathrm{ClO}_{4}\right)_{3} \cdot 4 \mathrm{II}_{2} \mathrm{O}$ crystal [1-3]. The $\mathrm{Nd}^{3+}$ ions are ninefold oxygen coordinated, both the carboxyl and carbonyl groups of diglicine are involved in the metal ion coordination, forming the chelate rings which stabilize the crystal structure. The X-ray data presented above seem to be important in explanation of the spectroscopic results which will be presented below.

Let us draw attention to Fig. 2. One can notice fine structure of the absorption bands, especially in the region of ${ }^{4} I_{9 / 2} \rightarrow{ }^{4} G_{5 / 2},{ }^{2} G_{7 / 2}$, and ${ }^{4} I_{9 / 2} \rightarrow{ }^{4} F_{5 / 2}$, ${ }^{2} H_{9 / 2}$ transitions [4-6]. Besides the strong components in the main region of those bands, the weak side bands at higher energies could be given by vibronic coupling and cooperative effect of lanthanide ion-pairs coupled in dimeric units, since the $\mathrm{Nd}-\mathrm{Nd}$ distance is relatively short $(\approx 3.99 \AA)$.

On the other hand, in the region of strong components of the hypersensitive transition, subtle splitting was recorded at high resolution of instrument.

In fact, when we detected this effect for the first time, it was supposed to be an exclusively registered spectrum, and we did not even consider it. However, our further investigations of other polymeric systems with drastically different compounds, namely lanthanide hydroxyperchlorates, confirmed the subtle splitting of electronic lines in the spectrum of neodymium ion at $5 \mathrm{~K}$. We tried to explain this effect later by Davydov splitting. At the present time there is still not enough evidence for distinguishing whether the exchange interactions lead to the observed phenomenon. 


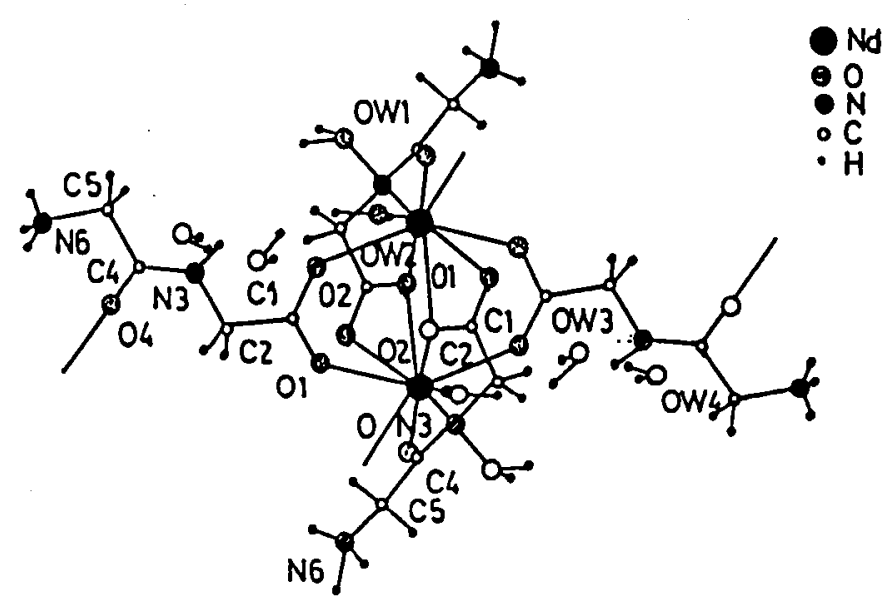

Fig. 1. View of the structure of $\mathrm{Nd}(\mathrm{Gly}-\mathrm{Gly})_{2}\left(\mathrm{ClO}_{4}\right)_{3} \cdot 4 \mathrm{H}_{2} \mathrm{O}$ crystal [1-3].
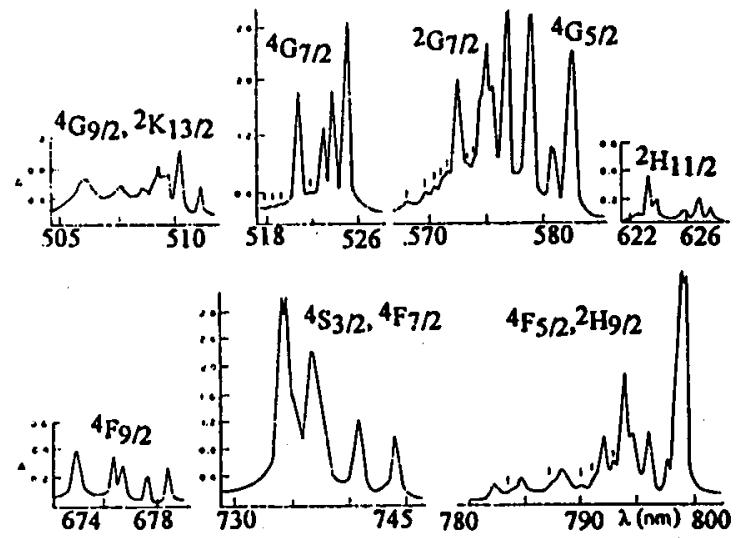

Fig. 2. Absorption spectrum of the $\mathrm{Nd}(\mathrm{Gly}-\mathrm{Gly})_{2}\left(\mathrm{ClO}_{4}\right)_{3} \cdot 4 \mathrm{H}_{2} \mathrm{O}$ single crystal at $5 \mathrm{~K}$ [4-6].

$\mathrm{Nd}_{2}(\mathrm{OII})_{3}\left(\mathrm{ClO}_{4}\right)_{3} \cdot 5 \mathrm{H}_{2} \mathrm{O}$ is the second structure, presented in Fig. 3 [7]. It is worth noting that this new class of compounds (two other hydroxyperchlorates have somewhat different composition) was synthesized by us first, and characterized using X-ray and spectroscopic methods. The results of the X-ray diffraction studies revealed the lanthanides to be eight- and ninefold coordinated, and the perchlorate ions to be strongly involved in coordination process acting as bridging bidentate, tridentate, tetradentate and hexadentate units [7, 8].

We did not intend to present the crystal structure of the latter compound; however, the arrangement of the chains in the fashion of a hexagonal closest packing of rods and their interconnection via $\mathrm{O} 13$ oxygen atoms by hydrogen bonding, as well as creation of one-dimensional infinite chain from centrosymmetric dimers, 


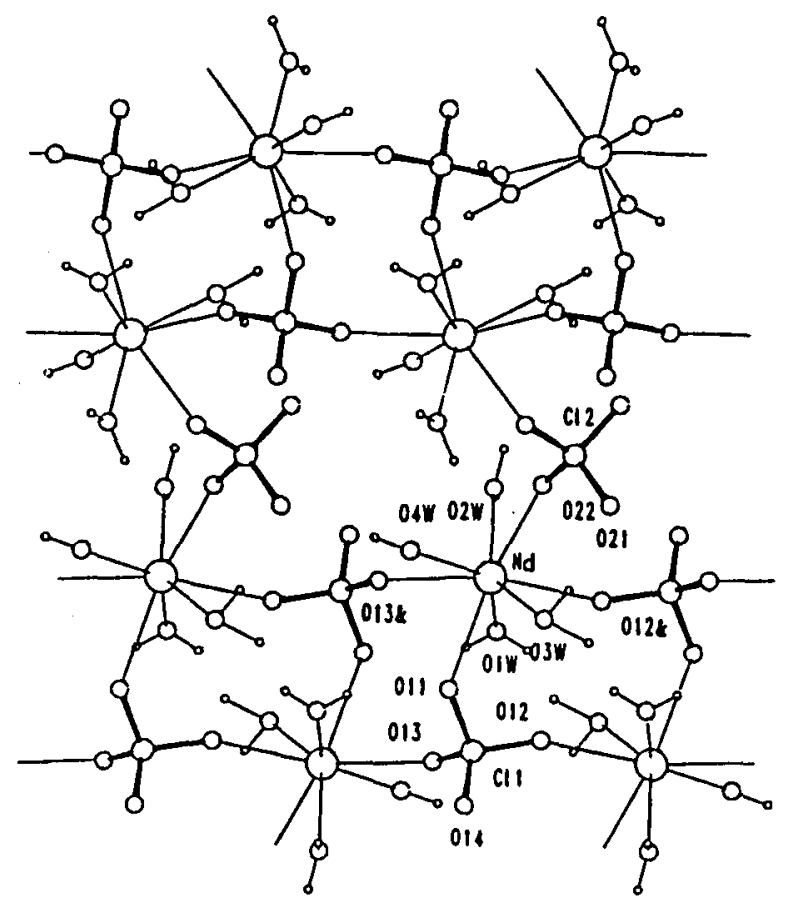

Fig. 3. Perspective view of a characteristic layer fragment of the $\mathrm{Nd}_{2}(\mathrm{OH})_{3}\left(\mathrm{ClO}_{4}\right)_{3} \cdot 5 \mathrm{H}_{2} \mathrm{O}$ crystal. The atoms of the crystallographic asymmetric unit are labelled as in the text ( $\&$ denotes symmetry-related equivalent atomic positions) [7].

convinced us to do that. The next figure pictures a view of it (Fig. 4). Figure 5 shows the high resolution absorption spectrum of neodymium single crystal at $5 \mathrm{~K}$ [9]. The nature of the bands resembles those presented before, and the mechanism of interactions of ionic pairs coupled in the polymer is the subject of our further investigations.

Now let us turn attention to the second class of compounds, that is to two types of europium squarates of formula: (1) $\mathrm{Eu}\left(\mathrm{C}_{4} \mathrm{O}_{4}\right)\left(\mathrm{IIC}_{4} \mathrm{O}_{4}\right)\left(\mathrm{II}_{2} \mathrm{O}\right)_{6} \cdot \mathrm{HI}_{2} \mathrm{O}$; (2) $\mathrm{Eu}_{2}\left(\mathrm{C}_{4} \mathrm{O}_{4}\right)_{3}\left(\mathrm{H}_{2} \mathrm{O}\right)_{8}$. The former one was obtained and analyzed by Petit et al., and later independently by us, by Petit and by Ribeiro [10-13].

The squarate anion, depending on the conditions of synthesis, can form monomeric type (1) and polymeric type (2) structures. In both of them soft electronic structure of squaric acid (given by delocalized electron of ring) leads to strong bonding of lanthanide ions. Figures 6 and 6 in [10] show schematically the structures of the bridging squarate anions involved in polymeric network and monomeric crystal of compound (1). Two types of squarate anions exist in the structure (2), bridging three-dentate and two-dentate, whereas in the monomeric compound the hydrogen bondings are formed involving water molecules and linking together two squarate rings (Fig. 6 in [10]). The monomeric sample is light yellow, while the polymeric one is intensive yellow. This property of the polymeric 


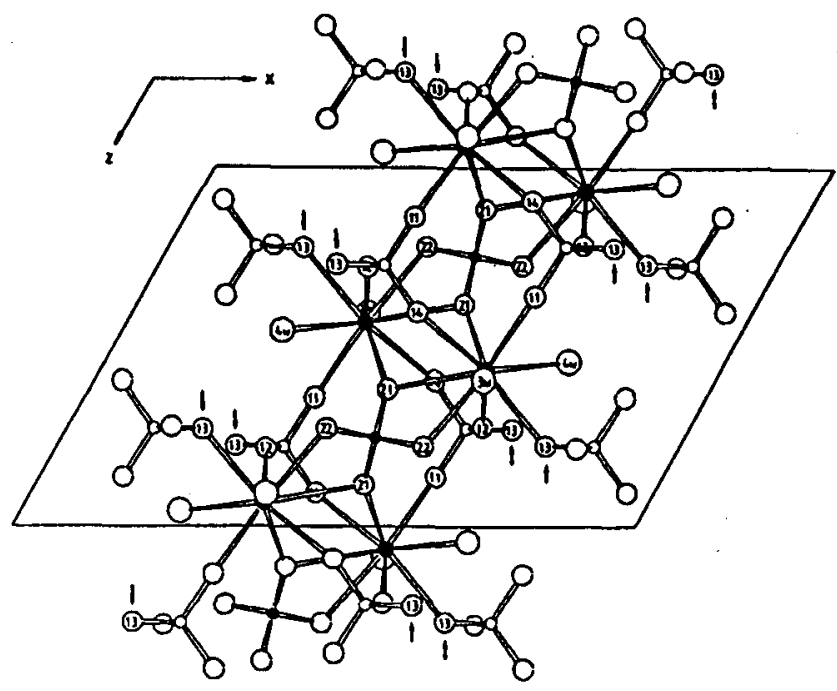

Fig. 4. One-dimensional infinite chain built-up from centrosymmetric dimers (see Fig. 2 in [8]). The 013 atoms are depicted by arrows for clarification of Fig. 4 [8] in praseodymium hydroxyperchlorate.

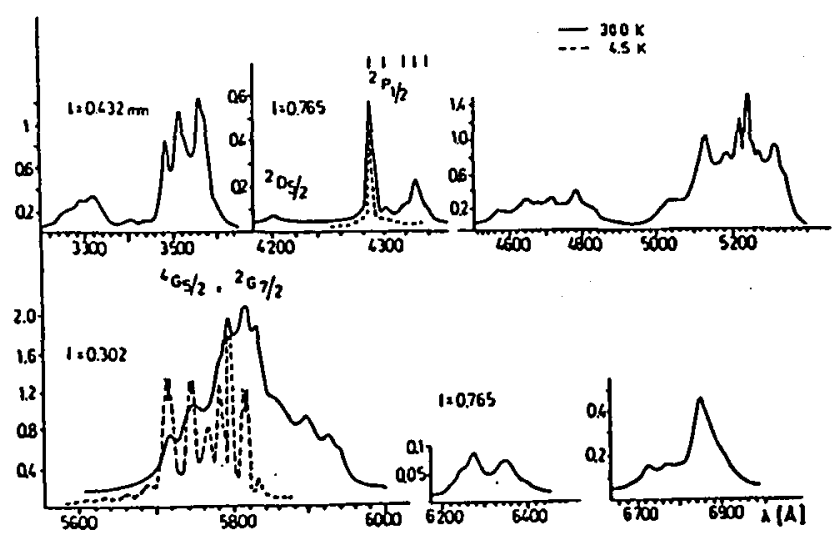

Fig. 5. Absorption spectra of the $\mathrm{Nd}_{2}(\mathrm{OH})_{3}\left(\mathrm{ClO}_{4}\right)_{3} \cdot 5 \mathrm{H}_{2} \mathrm{O}$ single crystal at room and liquid helium temperatures [9].

compound was explained by traces of $\mathrm{Eu}^{2+}$ ions [10]. So far there is no evidence for these traces.

On the one hand, the low lying CT transition $(\approx 350 \mathrm{~nm})$ which was observed by us in aqueous solution [13] could quench the emission from $f-d$ level of $\mathrm{Eu}^{2+}$ ion at $300 \mathrm{~K}$ (strong temperature quenching), but on the other hand, another explanation can be given, too.

In the polymeric systems the squarate ions can mediate in $\mathrm{M}-\mathrm{M}$ interaction; a covering of squarate ring in the structure may lead also to the ring coupling. This 


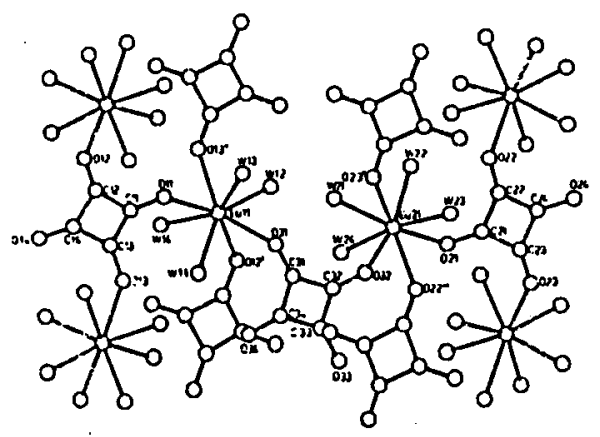

Fig. 6. An ORTEP drawing of the structure of $\mathrm{Eu}_{2}\left(\mathrm{C}_{4} \mathrm{O}_{4}\right)_{3}\left(\mathrm{H}_{2} \mathrm{O}\right)_{8}[10,11]$.

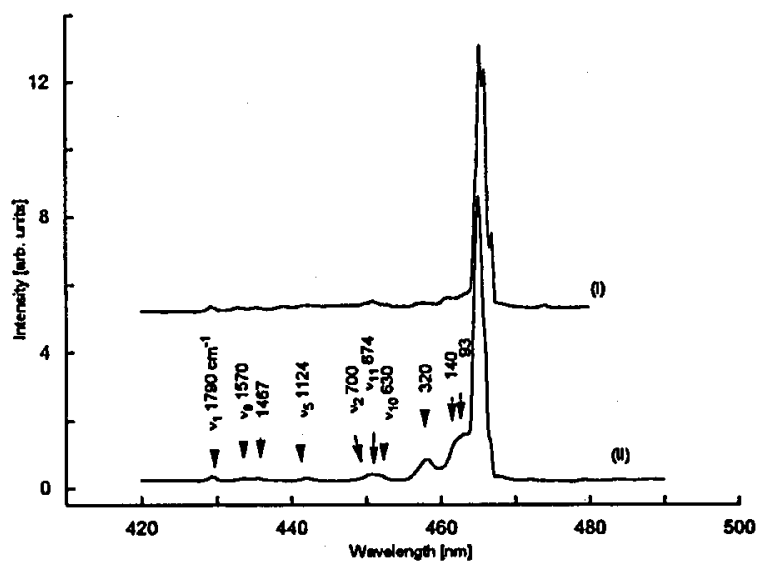

Fig. 7. Excitation spectra of compounds (1) and (2) in the region of ${ }^{7} F_{0} \rightarrow{ }^{5} D_{2}$ transition; $T=77 \mathrm{~K}[13]$.

last effect could be caused by $\pi$ coupling of squarate rings separated by $\approx 3.2 \AA$.

To solve this problem in detail we used EPR and $\gamma$-irradiation methods to increase $\mathrm{Eu}^{2+}$ ion concentration in the crystals. Three series of exposition changed nothing in the emission intensities. Neither at $300 \mathrm{~K}$ nor at $77 \mathrm{~K}$ the signals were received when using EPR method to detect the signals of $\mathrm{Eu}^{2+}$ ions before and after irradiation. Consequently, the most revealing factor which quenches luminescence seems to be the multiphonon relaxation, although the charge-transfer (CT) bands play an important role in the process.

The low temperature spectra exhibit relatively strong vibronic coupling, both with internal and ligand external modes. The excitation spectra of the two types of squarates (1 and 2) are presented in Fig. 7 in the area of ${ }^{7} F_{0} \rightarrow{ }^{5} D_{2}$ transitions. Confrontation of electronic spectrum with the Raman data allows the assignment of vibronic components at high energy of 0 -phonon lines. The components are 


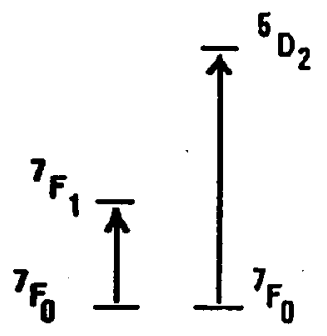

ion 1 ion 2

marked in the figures and are collected in [13]. The intensities of vibronic components in the region of internal ligand mode are comparable for the two types of monocrystals (monomeric and polymeric). However, drastical differences are observed in the $0-400 \mathrm{~cm}^{-1}$ range from 0 -phonon lines. This range of spectrum covers the cooperative interactions of pairs of ions coupled by squarate ligand. The observed phenomenon could be caused by double excitation of pairs of europium ions mediated by phonon, whose energy corresponds to splitting of ${ }^{7} F_{0} \rightarrow{ }^{7} F_{1}$ level. This could be explained in the following way: at $77 \mathrm{~K}$, an electronic excitation of ${ }^{7} F_{0} \rightarrow{ }^{5} D_{2}$ on one ion is coupled to ${ }^{7} F_{0} \rightarrow{ }^{7} F_{1}$ excitation on a neighbouring $\mathrm{Eu}^{3+}$ ion in the chain. The resulting transition corresponds to the sum of the two single excitations, leading to a high-energy side band of the ${ }^{7} F_{0} \rightarrow{ }^{5} D_{2}$ electronic origin. They can be denoted by ${ }^{7} F_{0(1)} \rightarrow{ }^{5} D_{2(1)}+{ }^{7} F_{1(2)}$ $\left(280 \mathrm{~cm}^{-1}\right)$ and ${ }^{7} F_{0(1)} \rightarrow{ }^{5} D_{2(1)}+{ }^{7} F_{1(2)}\left(303 \mathrm{~cm}^{-1}\right)$. Phonons with energy of 280 and $320 \mathrm{~cm}^{-1}$ most probably mediate this process, fitting well the splitting of ${ }^{7} F_{1}$ level.

The cooperative absorption was earlier observed and explained for europium systems by Buys et al. in $\mathrm{Eu}_{2} \mathrm{O}_{3}$ excitation spectra [14].

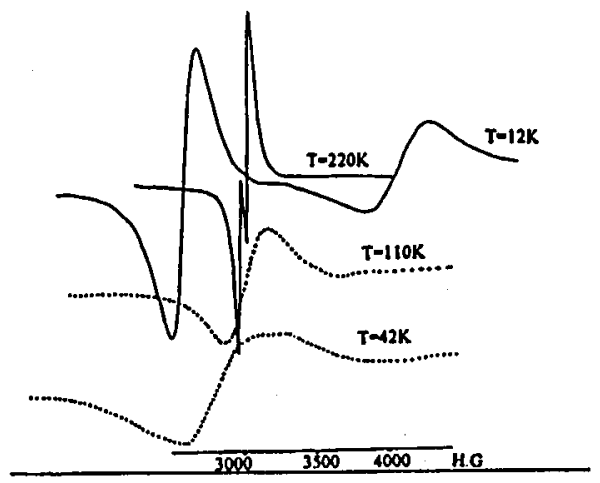

Fig. 8. EPR spectra of Nd-Cu-squarate crystals. The temperature dependence of the EPR spectra at an arbitrary orientation of the $(\mathrm{Cu}: \mathrm{Nd})_{2}\left(\mathrm{C}_{4} \mathrm{O}_{4}\right)_{3}\left(\mathrm{H}_{2} \mathrm{O}\right)_{11} \cdot 2 \mathrm{H}_{2} \mathrm{O}$ crystal [15].

Unresolved remains the problem whether the interaction between metal ion is mediated only by soft ligand structure in the chain and/or by $\pi$-coupling of the' squarate ring. We have synthesized new compounds substituting Eu and Nd ions by $\mathrm{Cu}$ ones, and applied EPR measurements at liquid helium temperature (Fig. 8) [15]. Two types of signals were detected; those of Nd ions at low temperature, and at $300 \mathrm{~K}$ the signals of $\mathrm{Cu}^{2+}$ ions, which disappear at $77 \mathrm{~K}$. Moreover, since the concentration of $\mathrm{Cu}^{2+}$ ions is low, this latter effect can be explained rather by $\mathrm{Nd}-\mathrm{Cu}$ interaction and it is most likely mediated by squarate ions. Of course, to exclude the ring coupling one needs additional experiments, under high pressure, 
where the distances between ring would be reduced, or by the sol-gel method, where formation of glass should compress the shells composed of rings.

Thus, there is as yet not enough evidence to distinguish between the latter two mechanisms of interaction. However, the most important factor in these interactions is polymeric structure.

Let us presi :It now "hot" results which can explain another type of interaction in pseudo-one-dimensional polymeric systems of lanthanide chloroacetates, and which we presented during the previous Conference. The data explain the role of $\mathrm{Cu}$ ion in this polymeric sample, the EPR data show Nd-Nd interaction and also the $\mathrm{Nd}-\mathrm{Cu}$ one $[15,16]$.

The second area of great interest is the role of coupled lanthanide ions in a dimer. Lanthanide ions coupled in pairs affect strongly the physical properties of systems under investigation. In fact, four types of cooperative dimer transitions were observed in the dimer spectra. Since all the crystal-field (CF) sublevels are further split by exchange or magnetic multipole interaction, transitions between the split levels are observed. The exchange interaction is of Ileisenberg type, and leads to splitting of the levels to few units. In measurements with high resolution of instrument the splitting is apparent in the optical lines in some cases. The effects detected in the two former spectra could be probably of this origin.

The cooperative processes in solid ionic systems were widely investigated by many authors; in molecular systeins of lanthanide carboxylates they were studied by Güdel and by us, both in polymeric and dimeric structures [16-19]. The complex structure of spectra was explained by exchange, superexchange, or phonon-mediated interaction between lanthanide ions coupled in a dimer by Ln-O-C-O-Ln bridge (on the basis of IR and Raman spectra). These interactions are limited by the Ln-Ln distance but, on the other hand, also by the type of bonding.

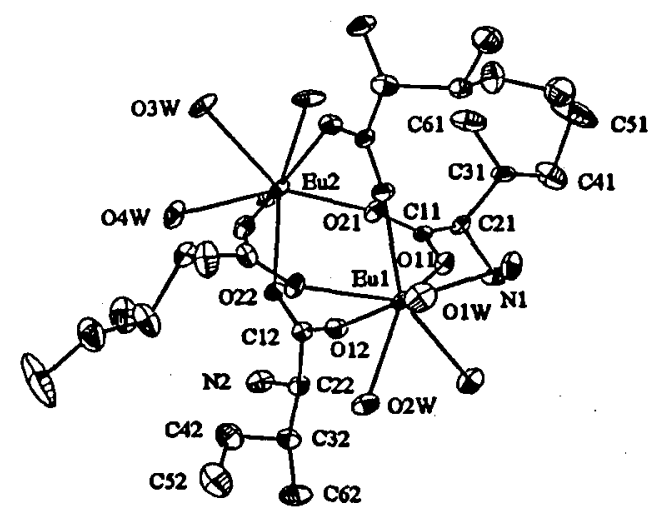

Fig. 9. Crystal structure of $\left[\mathrm{Eu}(\mathrm{L}-\mathrm{Ile})_{2}\left(\mathrm{H}_{2} \mathrm{O}\right)_{4}\right]_{2}\left(\mathrm{ClO}_{4}\right)_{6}$ complex [20]. The unit cell parameters: Eu:L-Ile: monoclinic, $C 2, Z=4, a=21.704, b=10.423, c=15.121$, $\beta=120.25$; Eu:D-Ile: triclinic, $P \overline{1}, Z=1, a=10.483, b=11.495, c=14.374, \alpha=73.27$, $\beta=65.69, \gamma=69.83$. 


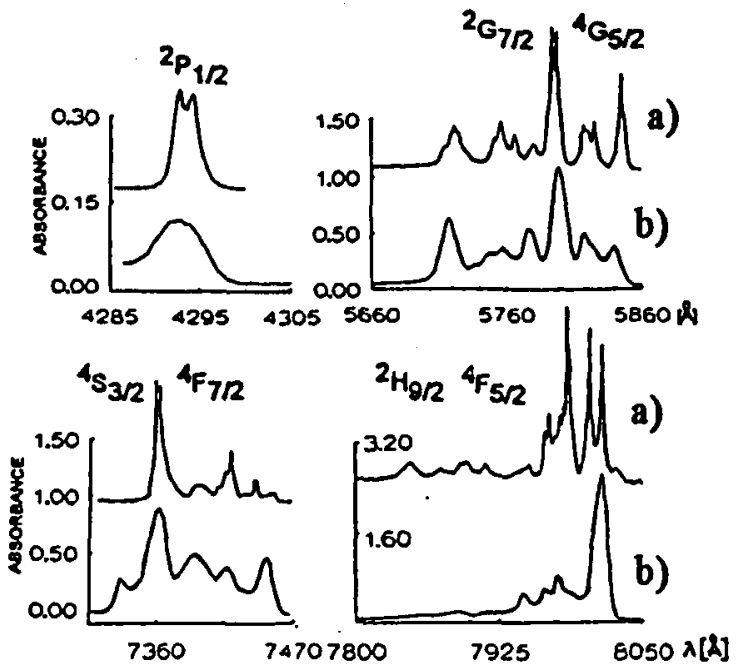

Fig. 10. Absorption spectra of $(a)\left[\mathrm{Nd}(\mathrm{L}-\mathrm{Ile})_{2}\left(\mathrm{H}_{2} \mathrm{O}\right)_{4}\right]_{2}\left(\mathrm{ClO}_{4}\right)_{6}$ and $(b)\left[\mathrm{Nd}(\mathrm{DL}-\mathrm{Ile})_{2}\left(\mathrm{H}_{2} \mathrm{O}\right)_{4}\right]_{2}\left(\mathrm{ClO}_{4}\right)_{6}$ single crystals at $5 \mathrm{~K}$.
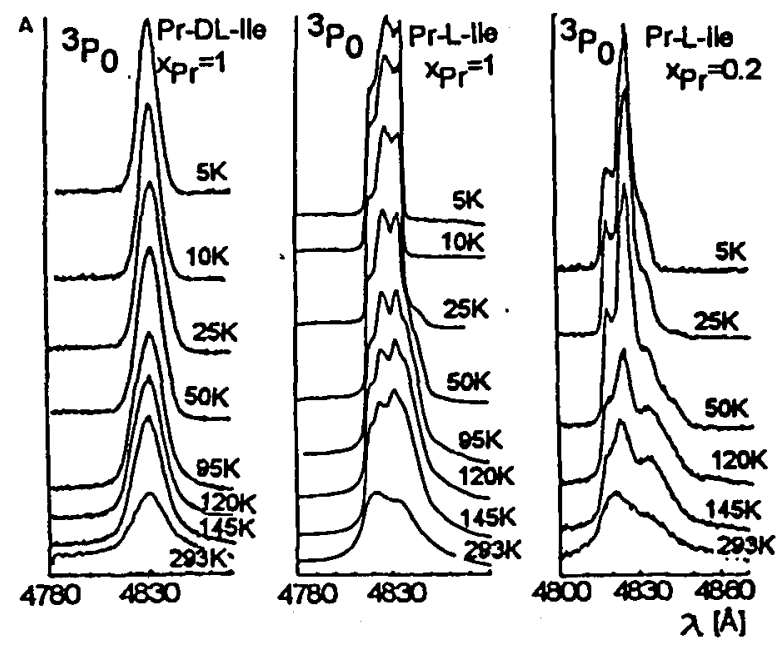

Fig. 11. Temperature dependence of ${ }^{3} H_{4} \rightarrow{ }^{3} P_{0}$ transition in the absorption spectra of the $\left[\mathrm{Pr}(\mathrm{DL}-\mathrm{Ile})_{2}\left(\mathrm{H}_{2} \mathrm{O}\right)_{4}\right]_{2}\left(\mathrm{ClO}_{4}\right)_{6}, \quad\left[\mathrm{Pr}(\mathrm{L}-\mathrm{Hle})_{2}\left(\mathrm{H}_{2} \mathrm{O}\right)_{4}\right]_{2}\left(\mathrm{ClO}_{4}\right)_{6}$, and $\left[\mathrm{Pr}_{0.2} \mathrm{La}_{0.8}(\mathrm{~L}-\mathrm{Ile})_{2}\left(\mathrm{H}_{2} \mathrm{O}\right)_{4}\right]_{2}\left(\mathrm{ClO}_{4}\right)_{6}$ single crystals [20].

The effect of interacting lanthanide ion pairs is much stronger in relatively covalent compounds.

Again two types of dimer structures will be presented now: (a) complexes with DL- and L-iso-leucine [20], and (b) lanthanide compounds with DL- and L-aminoliydroxamic acids [21].

Figures 9 and 1 in [21] show the dimer structures of crystals. Besides the 
evidence for the ligand chirality effect on the creation of the centro- and noncentrosymmetric dimer, in the above systems a role of the size and the kind of the ligand carbon chain on separation of Ln-Ln ions in the dimer, as well as on the spectroscopic properties of this dimeric system were found. The ligand chirality effect is excellently demonstrated both in the absorption spectra of the neodymium compound with L-handed and racemic ligand, and in the luminescence spectra of europium crystals. Figure 10 shows well the centrosymmetric dimer (bottom traces) and noncentrosymmetric dimers (upper one) in the absorption spectrum at $5 \mathrm{~K}$ of neodymium complexes. Broadening of bands in the centrosymmetric dimer confirms double excitation processes, the same concerns the additional weak side bands at higher energy in the L-handed system.

Since $\mathrm{Pr}^{3+}$ and $\mathrm{Nd}^{3+}$ ions are favourable in studies of ion-pairs interactions, the spectroscopic examinations of its pure complexes with DL- and L-iso-leucine were performed. The resulting absorption spectra at $5 \mathrm{~K}$ versus concentration of the active ions, as well as the temperature dependence of ${ }^{3} H_{4} \rightarrow{ }^{3} P_{0}$ transition are presented in Fig. 11.

The half-width of the ${ }^{3} \mathrm{H}_{4} \rightarrow{ }^{3} P_{0}$ band is equal to $76 \mathrm{~cm}^{-1}$, remaining the same for DL- and L-ligand forms, and there are no lower lying components when increasing temperature up to $300 \mathrm{~K}$ for the centrosymmetric dimer, where (like for the earlier systems) in the noncentrosymmetric dimers the respective components are narrow and exhibit drastically different trend when temperature raises. Suppose that the centrosymmetric dimer in the presented system is better isolated (for the reason of branched chain) and its $\Delta E$ is in a resonance with the lattice mode detected in Raman spectra at $76 \mathrm{~cm}^{-1}$. Suppose further that in the above systems the double excitation of coupled ions is involved. Resulting band width remains almost unchanged up to $150 \mathrm{~K}$ and the system looks like a disordered one.
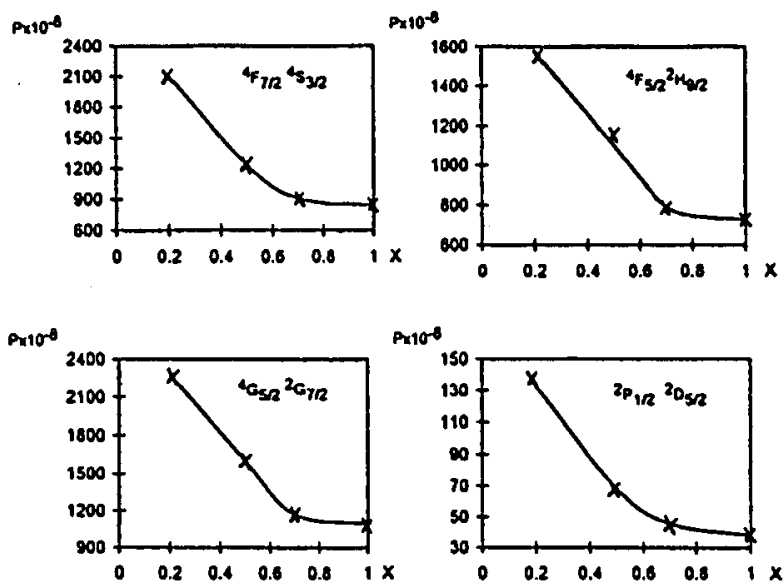

Fig. 12. The concentration dependence of selected oscillator strength values of $\mathrm{Nd}^{3+}$ ion for $\left[\mathrm{Nd}_{x} \mathrm{La}_{1-x}(\mathrm{~L}-\mathrm{lle})_{2}\left(\mathrm{H}_{2} \mathrm{O}\right)_{4}\right]_{2}\left(\mathrm{ClO}_{4}\right)_{6}$ compound [20]. 
This is the most unexpected result which we have found for our dimer systems (see Fig. 11).

The next dimer systems are, to our knowledge, the first compounds of lanthanides with aminohydroxamic acids which have been obtained in solid state. $\mathrm{X}$-ray analysis shows again the centro- and noncentrosymmetric systems, but structure of those dimer units is strengthened by the chelating properties of aminohydroxamic acid molecules, including $\mathrm{OH}$ bridge yet rarely known for lanthanides (see Fig. 1 in [21]).

Fluctuation of pII during the preparation procedure tends to include $\mathrm{IClO}_{4}$ molecules in crystal cavities and creation of dynamic hydrogen bonds, in the L-handed system. On the other hand, temperature lowering down to $\approx 40 \mathrm{~K}$ causes minor modifications in the structure and we could formulate the hypothesis about the intra-system conformation.

Low temperature X-ray is the only direct way to measure the distance between dimers and conformation of the structure.

Interactions of coupled ions are also manifested, beside these considered above, in irregularities of the intensities of electronic transitions and of double excitation, involving several electronic states (Fig. 12).

The calculated intensities of diluted single crystals do not show strictly linear dependence.

\section{Pseudodimer and monomeric compounds}

A pseudo-dimer system of the compound $\operatorname{Pr}(\mathrm{IImpa})_{4}(\mathrm{SCN})_{4} \mathrm{HgCl}$ (further Ln-IIg) with C.N. = 7 is demonstrated in Fig. 1 in [22].

The asymmetric surrounding of $\mathrm{Ln}$ ion and the effect of the heavy metal ion in neighbouring position to the Ln ion could affect the intensities of $f-f$ transitions. Moreover, the relatively short M-L distance and C.N. = 7, rare in lanthanide systems, make this mixed crystal interesting from the spectroscopic point of view. The emission spectra of europium single crystal are markedly strong in the region of ${ }^{5} D_{0} \rightarrow{ }^{7} F_{J}$ transition at 77 and $300 \mathrm{~K}$. Structure of bands indicates a symmetry close to $C_{2 v}$ or $C_{s}$. Vibronic coupling is well manifested both in the luminescence and excitation spectra (see tables in [22]). Intensities of $f-f$ transition were calculated for the single crystal case of $\mathrm{Pr}-\mathrm{Hg}$ compound, which is isomorphic with the $\mathrm{Eu}-\mathrm{IIg}$ one. Similarly, the temperature dependence of intensities was examined down to $6 \mathrm{~K}$ (Table I). Complex structure of bands, well recorded in the range of ${ }^{3} P_{J}$ bands, suggests deviation from point symmetry of ideal coordination polyhedra for C.N. $=7$. The oscillator strength values calculated at room temperature do not point at drastically high intensities, which could be expected for the system with such asymmetry.

Let us mention now few words about octahedral $\mathrm{Eu}(\mathrm{Impa})_{6}\left(\mathrm{ClO}_{4}\right)_{3}$ crystals.

Two modifications of this compound were synthesized, the synthesis procedure being a bit different. Both the samples have $O_{h}$ symmetry, with unit cell parameters $a_{\mathrm{Nd}}=19.222(1)$, and $a_{\mathrm{Eu}}^{\prime}=19.091$.

Figure 13 shows the X-ray view of the structure of neodymium single crystal [23]. This structure was solved by us and indicates statistical distribution of three $\mathrm{N}\left(\mathrm{CII}_{3}\right)_{2}$ groups in four equivalent positions, with the occupancy factor $3 / 4$ 
TABLE I

The oscillator strength values of $f-f$ transitions in $\operatorname{Pr}(\mathrm{SCN})_{4}(\mathrm{Hmpa})_{4} \mathrm{HgCl}$ crystal spectra.

\begin{tabular}{l|c|c|c}
\hline \hline Transitions & \multicolumn{3}{|c}{$P \times 10^{8}$} \\
& \multicolumn{2}{|c}{$C_{\mathrm{Pr}}=1.1595\left[\mathrm{~mol} / \mathrm{dm}^{3}\right]$} \\
\cline { 2 - 3 } & \multicolumn{2}{|c|}{$293 \mathrm{~K}$} & $5 \mathrm{~K}$ \\
\cline { 2 - 3 } & $x$ & $y$ & \\
\hline${ }^{3} H_{4} \rightarrow{ }^{3} P_{2}$ & 1397.92 & 1313.58 & 1447.64 \\
${ }^{3} I_{4} \rightarrow{ }^{3} P_{1}{ }^{1} I_{6}$ & 560.69 & 550.61 & 392.45 \\
${ }^{3} H_{4} \rightarrow{ }^{3} P_{0}$ & 281.62 & 281.39 & 105.50 \\
${ }^{3} H_{4} \rightarrow{ }^{1} D_{1}$ & 410.04 & & 291.51 \\
${ }^{3} H_{4} \rightarrow{ }^{1} G_{4}$ & 44.46 & & \\
${ }^{3} H_{4} \rightarrow{ }^{3} F_{4}$ & 130.09 & & \\
${ }^{3} H_{4} \rightarrow{ }^{3} F_{3}$ & 564.06 & &
\end{tabular}

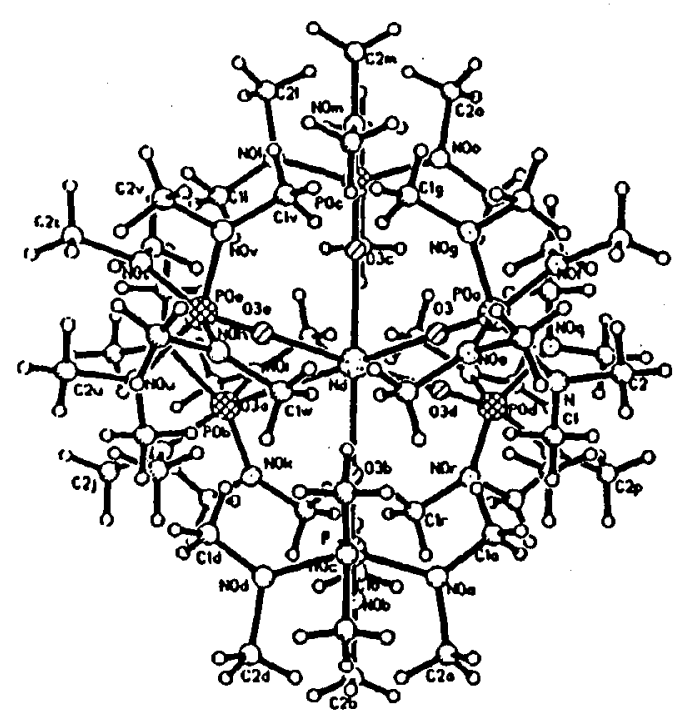

Fig. 13. General view of the molecule of $\mathrm{Nd}(\mathrm{Hmpa})_{6}\left(\mathrm{ClO}_{4}\right)_{3}$ with labelling scheme [23].

resulting from $\mathrm{P}-\mathrm{O}$ rotation. Each metal ion is coordinated to six IImpa molecules through oxygen atoms of the PO group, with the $\mathrm{Nd}-\mathrm{O}$ bond lengths of $2.340(8) \AA$.

Metal ions occupy the symmetry centres of ideal $O_{h}$ arrangement. The $\mathrm{Nd}-\mathrm{O}-\mathrm{P}$ entities are strictly linear with half-full angle. The room temperature emission spectra of the two modifications of crystals mentioned above are the same, although drastical differences were recorded when temperature was lowered down to $77 \mathrm{~K}$ (see Fig. 14). 


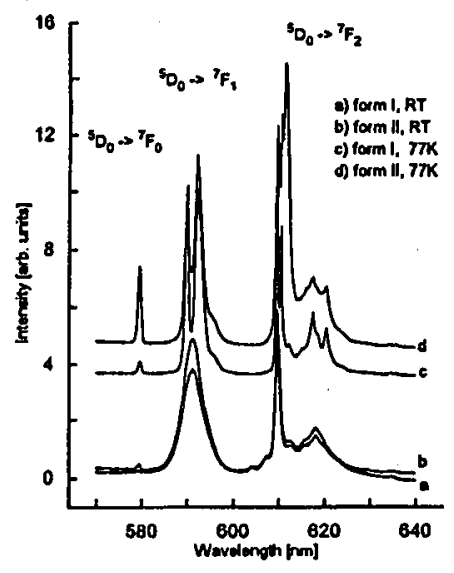

Fig. 14. Luminescence spectra of the $\left[\mathrm{Eu}(\mathrm{Hmpa})_{6}\left(\mathrm{ClO}_{4}\right)_{3}\right.$ complexes [23].

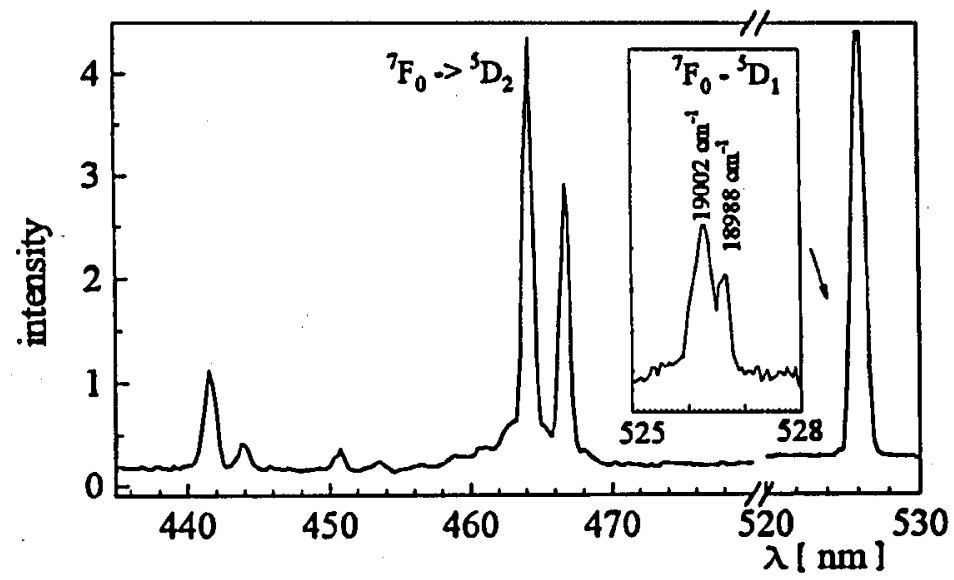

Fig. 15. Excitation spectrum of the $\left[\mathrm{Eu}(\mathrm{Hmpa})_{6}\left(\mathrm{ClO}_{4}\right)_{3}\right.$ at $77 \mathrm{~K}$ [23].

The first type of the crystal possesses optical properties similar to those of $\mathrm{Eu}(\mathrm{AP})_{3}\left(\mathrm{ClO}_{4}\right)_{3}$ crystal reported by Richardson et al. [24] and by us [25]. The splitting of ${ }^{7} F_{1}$ level $\left(\Delta E=61 \mathrm{~cm}^{-1}\right)$ in the emission spectrum is relevant to the splitting of this level observed in antipyrine crystals $\left(64 \mathrm{~cm}^{-1}\right)$, although relative intensities of the sharp lines of ${ }^{5} D_{0} \rightarrow{ }^{7} F_{J}$ electronic transitions are not in the same relation as the respective ones in $\mathrm{Eu}(\mathrm{AP})_{6}\left(\mathrm{ClO}_{4}\right)_{3}$.

It is also interesting to note that all the types of modes: lattice, metal-ligand, and ligand internal ones, appear in the $f-f$ transition for both neodymium and europium complexes at 77 and $5 \mathrm{~K}$ (see Table III).

Let us confront the results of emission and excitation spectra obtained at low temperatures (Figs. 14 and 15). First of all, one should note that electronic lines are strong, as for the ideal octahedral symmetry determined by X-ray analysis. 
TABLE II

Vibronic components in excitation spectra of $\mathrm{Eu}(\mathrm{Hmpa})_{6}\left(\mathrm{ClO}_{4}\right)_{3}$ crystal.

\begin{tabular}{l|c|c|c|c}
\hline \hline Energy [nm] & Energy [cm-1] & $\begin{array}{c}\Delta E \text { (from } \\
\text { 0-phonon line } \\
\left.21417 \mathrm{~cm}^{-1}\right)\end{array}$ & $\begin{array}{c}\Delta E \text { (from } \\
\text { 0-phonon line } \\
\left.21537 \mathrm{~cm}^{-1}\right)\end{array}$ & Assignment \\
\hline 466.9 & 21417 & & & \\
464.3 & 21537 & & 75 & $\delta(\mathrm{OEuO})$ \\
462.7 & 21612 & 195 & - & $\nu(\mathrm{EuO})$ \\
461.1 & 21687 & 270 & 176 & $\delta(\mathrm{OEuO})$ \\
460.55 & 21713 & - & - & $\nu(\mathrm{EuOP})$ \\
459.2 & 21777 & 360 & 371 & $\nu(\mathrm{EuOP})$ \\
456.45 & 21908 & - & 518 & $\delta(\mathrm{OPN})$, \\
453.4 & 22055 & $638^{*}$ & & $\nu_{s}(\mathrm{PN})^{*}$ \\
450.75 & 22185 & - & 648 & $\nu_{s}(\mathrm{PN})$ \\
444.0 & 22522 & 1105 & - & $\nu(\mathrm{OP})$ \\
441.55 & 22647 & - & 1110 & $\nu(\mathrm{OP})$
\end{tabular}

TABLE III

The oscillator strength values of $f-f$ transitions in $\mathrm{Nd}(\mathrm{Hmpa})_{6}\left(\mathrm{ClO}_{4}\right)_{3}$ crystals $[23,26]$.

\begin{tabular}{c|c|c|c}
\hline \hline$S^{\prime} L^{\prime} J^{\prime}$ & Nd aquo-ion & $\begin{array}{c}\text { Nd(Hmpa) } \\
\text { single crystal }\end{array}$ & $\begin{array}{c}\text { Nd(AP) } \\
\text { single crystal }\end{array}$ \\
\hline${ }^{4} F_{3 / 2}$ & 214.4 & 27.8 & 56.2 \\
${ }^{4} F_{5 / 2},{ }^{2} H_{9 / 2}$ & 852.0 & 85.1 & 234.8 \\
${ }^{4} F_{7 / 2},{ }^{4} S_{3 / 2}$ & 885.4 & 77.6 & 248.3 \\
${ }^{4} G_{5 / 2},{ }^{2} G_{7 / 2}$ & 967.9 & 395.1 & 590.0 \\
${ }^{2} K_{13 / 2},{ }^{4} G_{7 / 2},{ }^{4} G_{9 / 2}$ & 688.5 & 117.3 & 189.9 \\
${ }^{2} G_{9 / 2},{ }^{2} D_{3 / 2},{ }^{4} G_{11 / 2},{ }^{2} K_{15 / 2}$ & 191.2 & 40.1 & 32.8 \\
${ }^{2} P_{1 / 2},{ }^{2} D_{5 / 2}$ & 39.6 & 11.2 & 21.3 \\
${ }^{4} D_{3 / 2},{ }^{4} D_{5 / 2},{ }^{4} D_{1 / 2},{ }^{2} I_{11 / 2}$ & 906.8 & 166.1 & -
\end{tabular}

This implies a deviation from the ideal octahedral symmetry of $\mathrm{Eu}^{3+}$ ion at low temperatures. Besides, the emission spectrum in the region of ${ }^{5} D_{0} \rightarrow{ }^{7} F_{1}$ magnetic origin is much more complex compared to ${ }^{7} F_{0} \rightarrow{ }^{5} D_{1}$ transition observed in the excitation spectrum.

Additional strong lines are observed in the ${ }^{5} D_{0} \rightarrow{ }^{7} F_{1}$ region of the emission spectra, their location falls in energies almost resonant with the ligand vibrational mode (from ${ }^{7} F_{0}$ level). 
Table II compiles some of the assigned vibronic components observed in the excitation and emission spectra. Calculated intensities of $f-f$ transitions for neodymium crystals are collected in Table III. There are also included the oscillator strength values obtained for neodymium crystals with antipyrine. Note lower intensities of $f-f$ transitions in the crystal under studies than those in neodymium antipyrine complex. Those latter results confirm well the $O_{h}$ symmetry in the spectra of crystals obtained at room temperature [26].

Luminescence spectra of the second type of crystal at low temperatures show additional strong electronic components, which can be considered as an effect of dynamic processes in solid. Rotation of $\mathrm{O}-\mathrm{P}-\mathrm{N}$ bonds is stopped at particular positions, most probably leading to further lowering of symmetry of the system under investigation.

These latter effects will be carefully analyzed going down, step by step, with temperature, and will be the subject of our studies in progress.

\section{Acknowledgments}

The author would like to thank her collaborators: G. Oczko, E. Huskowska, P. Gawryszewska, and W. Amirkhanov for their help in the research and preparation of this work. A financial support from the State Committee for Scientific Research is also acknowledged.

\section{References}

[1] J. Legendziewicz, I. Csöregh, E. IIuskowska, P. Kierkegaard, in: Twelfth Europ. Cryst. Meeting, Moscow, Vol. 2, WINITI, USSR Academy of Sciences, Moskva 1989, p. 383.

[2] J. Legendziewicz, in: Excited States of Transition Elements, Eds. B. Jeżowska-Trzebiatowska, J. Legendziewicz, W. Stręk, World Sci. Publ. Co. Pte., Singapore 1989 , p. 228.

[3] I. Csöregh, E. Huskowska, J. Legendziewicz, Acta Crystallogr. 48, 109 (1992).

[4] J. Legendziewicz, E. Huskowska, W. Ryba-Romanowski, A. Kozanecki, in: Excited States of Transition Elements, Eds. W. Stręk, W. Ryba-Romanowski, J. Legendziewicz, B. Jeżowska-Trzebiatowska, World. Sci. Publ. Co. Pte., Singapore 1992, p. 391; ilid., p. 367.

[5] E. Huskowska, J. Legendziewicz, Polyhedron 12, 2387 (1993).

[6] J. Legendziewicz, in: Excited States of Transition Elements, Eds. W. Stręk, W. Ryba-Romanowski, J. Legendziewicz, B. Jeżowska-Trzebiatowska, World. Sci. Publ. Co. Pte., Singapore 1992, p. 149.

[7] I. Csöregh, E. Huskowska, A. Ertan, J. Legendziewicz, P. Kierkegaard, Acta Chim. Scand. 43, 829 (1989).

[8] Th. Schleid, G. Meyer, G. Oczko, J. Legendziewicz, J. Alloys Comp. 176, 337 (1991); E. Iluskowska, J. Legendziewicz, Th. Schleid, G. Meyer, Mater. Chem. Phys. 31, 117 (1992).

[9] E. Huskowska, J. Legendziewicz, J. Hanuza, Polyhedron 9, 659 (1990).

[10] J.F. Petit, A. Gleizes, J.Ch. Trombe, Inorg. Chim. Acta 167, 51 (1990).

[11] E. Huskowska, T. Głowiak, J. Legendziewicz, G. Oremek, J. Alloys Comp. 179, 13 (1992). 
[12] S.J.L. Ribeiro, R.R. Gonçalves, L.F.C. de Oliveira, P.S. Santos, J. Alloys Comp. 216, 61 (1994).

[13] E. Huskowska, J. Legendziewicz, P. Drożdzewski, Proc of this Conf. (Part II), Acta Phys. Pol. A 90, (1996).

[14] M. Buys, A. Meijerink, G. Blasse, J. Lumin. 37, 8 (1987).

[15] V.K. Voronkova, Yu.V. Yablokov, E. Huskowska, J. Legendziewicz, in: Proc. Winter Workshop on Coordination Chemistry, Karpacz (Poland) 1995, Ed. B. Żurowska, Faculty of Chemistry, University of Wroclaw, Wrocław 1995, p. 65 and a paper in preparation.

[16] J. Legendziewicz, J. Appl. Spectrosc. 62, 191 (1995).

[17] M.P. Hehlen, H. Reisen, H.V. Güdel, Inorg. Chem. 30, 2273 (1991).

[18] M.P. Hehlen, H.V. Güdel, J. Chem. Phys. 98, 1768 (1993).

[19] J. Legendziewicz, G. Oczko, W. Stręk, J. Hanuza, Eur. J. Solid State Inorg. Chem. 32, 95 (1995).

[20] J. Legendziewicz, Z. Ciunik, P. Gawryszewska, J. Sokolnicki, Polyhedron, in press; J. Legendziewicz, Z. Ciunik, P. Gawryszewska, J. Sokolnicki, J. Alloys Comp. 225, 372 (1995); J. Legendziewicz, Z. Ciunik, P. Gawryszewska, J. Sokolnicki, Acta Phys. Pol. A 84, 917 (1993).

[21] J. Legendziewicz, P. Gawryszewska, E. Galdecka, Z. Galdecki, Proc of this Conf. (Part II), Acta Phys. Pol. A 90, (1996).

[22] E. Galdecka, Z. Gałdecki, W. Amirkhanov, K. Kern, J. Legendziewicz, Proc of this Conf. (Part II), Acta Phys. Pol. A 90, (1996).

[23] E. Galdecka, Z. Gałdecki, E. Huskowska, W. Amirkhanov, J. Legendziewicz, paper in preparation.

[24] M.T. Berry, A.F. Kirby, F.S. Richardson, Mol. Phys. 66, 723 (1989); M.T. Berry, F.S. Richardson, ibid. 66, 703 (1989).

[25] W. Stręk, J. Legendziewicz, E. Huskowska, E. Lukowiak, Acta Phys. Pol. A 84, 979 (1993).

[26] E. Huskowska, J. Legendziewicz, paper in preparation. 